\title{
Roberto Esposito: comunidade, biopolítica e imunização
}

Guilherme F. W. Radomsky'

Communitas: origen y destino de la comunidad. Buenos Aires: Amorrortu Editores, 2003. $216 \mathrm{p}$.

Immunitas: the protection and negation of life. Cambridge; Malden: Polity Press, 20I I. 207 p. Bios: biopolítica e filosofia. Lisboa: Edições 70, 2010. 276 p.

Third person: politics of life and philosophy of the impersonal. Cambridge; Malden: Polity Press, 2012. $177 \mathrm{p}$.

\section{Resumo}

Neste ensaio, examino quatro obras do filósofo Roberto Esposito (Communitas, Immunitas, Bios e Third Person) por meio do eixo "vida - imunidade - experiência” para articulá-lo a dois temas centrais em seus escritos: biopolítica e comunidade. O objetivo consiste em realizar um balanço dos livros e discutir elementos das obras do autor que apontem para uma reflexão sobre a política contemporânea. Esposito analisa a biopolítica de maneira distinta de outros importantes pesquisadores que abordam o tema, tais como Foucault e Agamben, e sua contribuição original está em articulá-la ao problema da imunização.

Palauras-chave: Biopolítica. Experiência. Paradigma da imunização.

\section{Introdução}

Uma surpreendente afirmaçáo de Peter Sloterdijk, no seu Regras para o parque Humano, sugere um ponto de partida para investigarmos a obra de Roberto Esposito. Em texto oriundo de uma polêmica palestra dada em seu país, Sloterdijk (2000, p. 48) é categórico: "[...] a manutenção de seres humanos em parques ou cidades surge como tarefa zoopolítica". O problema residiria ainda no fato de que as pessoas não são somente mantidas neste parque

1 Professor do Departamento de Sociologia e dos Programas de Pós-Graduação em Sociologia (PPGS) e Desenvolvimento Rural (PGDR) da Universidade Federal do Rio Grande do Sul (UFRGS).

E-mail: guilherme.radomsky@ufrgs.br. 
temático ou zoológico, mas ficam neles por si mesmas. Uma interpelação grave ou uma orientação sobre o destino da sociedade e da política na modernidade?

Roberto Esposito, filósofo italiano, publicou uma sequência de livros que interagem profundamente - mesmo que de modo indireto - com esta provocação de Sloterdijk. Em seus escritos encontramos diálogos e problemáticas cujas ramificaçóes avançam para um debate em que se entrelaçam autores como Nietzsche, Bataille, Heidegger, Benjamin, Schmitt, Weil, Arendt, Foucault e Agamben. Communitas, Immunitas, Bios e Third Person são obras densas que exigem paciência do leitor, ainda que o prendam em razão das fabulosas constelaçóes conceituais. Filósofo ainda pouco comentado no Brasil, seus livros têm sido traduzidos para diversas línguas.

Neste ensaio, abordo temas de quatro de seus principais livros (Communitas, Immunitas, Bios e Third Person) por meio do eixo "vida - imunidade - experiência" para articulá-lo a dois caros assuntos que importam à política contemporânea: a biopolítica e o comunitarismo. Esposito analisa a biopolítica de maneira distinta de outros importantes pesquisadores que abordam o tema, tais como Foucault e Agamben, e sua contribuição original está em articulá-la ao problema da imunização.

\section{Comunidade, dádiva e dívida}

Communitas foi lançado originalmente em 1998 e trata de dialogar com o tema da comunidade no pensamento filosófico atual, especialmente com Jean-Luc Nancy ${ }^{2}$. Esposito inicia decifrando a etimologia do termo e as contradiçóes na reflexão ocidental, mostrando que - ao mesmo tempo em que a comunidade é algo comum, coletivo -, ela também se atrela ao pertencer e ao cercamento. Porém, a origem da palavra é vinculada especialmente ao termo munus, que lhe dá o significado de uma obrigação de dar, um dever como um encargo. Estamos em face de uma impropriedade e um nada do sujeito,

2 Nancy (2003, p. 10), ao comentar o trabalho de Esposito, expõe sua relevância: "Este trabajo de pensamiento se impuso por un motivo terrible, que la historia de nuestro siglo [...] no ha cesado de brindarnos, a tal punto que su recuerdo de tan agobiante se torna inevitable: en nombre de la comunidad, la humanidad - ante todo en Europa - puso a prueba una capacidad insospechada de autodestrucción”. A comunidade, enquanto reflexão filosófica, é central em Nancy (199I). Outra importante apresentação de Esposito é realizada também por Campbel (2008) na versão em língua inglesa do liuro Bíos. 
que à comunidade deve desde sempre. Communitas é o conjunto de pessoas, afirma o autor, ligadas por estarem em débito; não por um "mais" e sim por um "menos" que as coloca em dívida.

Distintos planos deste debate são mobilizados pelo autor, tais como os argumentos em Hobbes, Rousseau, Kant, Heidegger e Bataille, alguns dos quais cabem aqui examinar por meio dos meandros que o autor italiano nos conduz. Hobbes é central na reflexão por uma razão fundadora: a filosofia hobbesiana desconfia da comunidade, pois o vínculo humano é a eterna tentativa da opressão de uns sobre outros. Por isso, para Hobbes o Estado como um contrato significa a dessocialização do vínculo; o corpo político é a união dos homens, não o acordo. Esposito afirma que "[...] si la relación entre los hombres es de por si destructiva, la unica salida es la destrucción de la relación misma" (ESPOSITO, 2003, p. 64).

Esposito começa a tocar em um dos temas que seráo nucleares em sua obra. Em Hobbes, aparece o problema de como imunizar os seres humanos contra as relaçóes sociais potencialmente destrutivas. A imunidade, que neste momento podemos associar a “[...] não dever", não estar em débito com ninguém, apresenta-se como o inverso da comunidade, na qual o excesso de laços e dívidas encapsulam os sujeitos (2003, p. 39-40). Estaria a modernidade ligada de maneira umbilical à história de destruição do laço comunitário ao romper obrigaçóes e pertencimentos? Seria a imunidade antitética à vida em comunidade? Retornarei ao tópico e, por ser problema capital para o autor, este será o fio condutor que utilizarei para enredar os diferentes momentos do pensamento de Esposito.

Ainda na paisagem da filosofia moderna, o autor explora o contraponto a Hobbes em Rousseau. Em Rousseau, discordando do filósofo inglês, o que existe anterior ao Estado é um não vínculo. Nada existe antes do pacto, sequer comunidade. A comunidade está a ser buscada; porém, existe enquanto algo metafísico também e dá um horizonte de reflexáo possível, assunto brindado por Kant ao ler Rousseau. "La comunidad - en su significado más amplio de relación entre los hombres - no es uno de los tantos contenidos posibles de la filosofia, tampoco uno de sus problemas. Es su forma misma [...]", escreve o autor sobre Kant (ESPOSITO, 2003, p. 113). 
Entretanto, será em George Bataille que Esposito encontrará os aspectos mais controversos, problemáticos e simultaneamente vindouros a respeito da origem e do destino da comunidade. "Para Heidegger el cum es el molde originario que define desde el inicio nuestra condición; para Bataille", segue Esposito, "[...] constituye la zona-limite que no podemos experimentar sin perdernos. Por eso no podemos 'estar' en él más que esos breves instantes - la risa, el sexo, la sangre - en los que nuestra existencia toca a la vez su ápice y su precipicio" (2003, p. 197). Battaile está obstinado a colocar nesta zona limite a experiência interior, aquí no sentido do limite possível. Se em Benjamin (1985a, 1985b) a erfahrung é uma experiência enquanto travessia, Battaille a suplementa com uma viagem no vazio e sem volta, experiência que leva o sujeito para fora de si - é a própria experiência que experimenta e, assim, dessubjetivisa. Essa "tentação" retornará mais adiante em sua obra, especialmente na aproximação com Deleuze e o impessoal.

É somente nesse trânsito intenso entre o tudo e o nada da comunidade da lei que preserva a comunidade sob pena de sua destruição (DONÀ, 2006) -, entre o enfrentar o totalitário e o individualismo, que a comunidade pode se experimentar. No festejo da vida e da energia humana, junto à morte e ao sacrifício - o dar sem retribuição e gratuito: a vida que se arrisca a tocar a morte.

\section{Imunização contra a comunidade}

Lançando Immunitas em 2002 na Itália, Esposito aprofunda as relaçóes antitéticas à comunidade com o problema conceitual e histórico da imunidade. Uma das características do livro, comparado ao anterior, é o espaço concedido aos problemas da lei para a vida humana. Por tal razáo que Niklas Luhmann e Walter Benjamin aparecem com frequência, particularmente referente ao último o ensaio sobre a crítica da violência. Como se insere o problema da imunidade aqui? Se a comunidade pode eventualmente aniquilar a existência do indivíduo, a imunidade virá a isentá-lo da dívida, no entanto ela mesma (a imunizaçáo como processo) se amparará na violência. Se a imunizaçáo se assemelha a um "remédio" contra a violência que ameaça o ser humano, a mesma violência virá a caracterizar os procedimentos imunitários. Para o autor, este é o "curto-circuito que Benjamin reconhece na figura ambivalente da gewalt [violência], entendida como o entrelaçamento inseparável entre lei e força 
[...]" (p. 10-11) $)^{3}$, fazendo referência ao complexo ensaio do autor alemão escrito no início dos anos $1920^{4}$. Assim, um dos argumentos fundamentais de Immunitas se concentra nesta relaçáo e, ademais, o que se exige da "lei é imunizar a vida de seu impulso irresistível de superar a si mesma”. Em direção a sobrepujar o estado de mera vida biológica - tema também de Agamben (2002), mas que Esposito dá soluçáo distinta, e para o qual retornarei adiante - , a sociedade moderna percebeu a vida como zona que exige controle a ser realizado pela lei. Somente assim é possível administrá-la e normalizá-la (ESPOSITO, 2011, p. 31-32).

Repetem-se alguns dilemas de Communitas: como controlar essa vida humana desejante? Se a comunidade é algo na qual nascemos e para a qual devemos sempre, a sociedade moderna individualista se constitui na tentativa de imunização: imunizamo-nos contra o perigo de sermos destruídos pelo coletivo da comunidade. E sobre a lei, o mais fundamental é que esta não consiste em um procedimentalismo ad hoc; ao inverso, a lei entra como um modo de antecipaçáo, decidir o veredicto antes do julgamento.

No direito moderno, o que paira sobre todos nós é a culpa atribuída potencialmente a todos: "A vida náo é julgada porque é culpada; a vida é tornada culpada para que possa ser julgada - e condenada" (p. 32). No rastro deste problema, Agamben assinalou a perspicácia de Kafka: no decorrer de $O$ processo, ficamos sabendo que este não tem seu ápice no destino, na consequência, ou seja, na punição. Como a essência da lei é o processo, inocência e culpa perdem a importância. "O julgamento é em si mesmo a finalidade, e isso - já foi dito - constitui o seu mistério, o mistério do processo" (AGAMBEN, 2008, p. 28).

Para Nalli (2013, p. 83): “[...] a novidade e a contribuição de Esposito ao tema residem, inicialmente, em fornecer a primeira elaboração sistemática do paradigma imunitário e, principalmente, em demonstrar a relaçáo simétrica que existe entre imunidade e comunidade".

De um ponto de vista sociológico, pode-se interpretar o problema da imunizaçáo como entendida na medicina. Um médico, com vistas a formar

3 As citações diretas em língua inglesa foram livremente traduzidas.

4 Ensaio traduzido para a língua portuguesa em uma nova versão com título "Sobre a crítica do poder como violência", publicado na coletânea Benjamin (20I3). Para análise do texto em relação a temas que importam a este ensaio, remete-se o leitor para Barbosa (2013) e Seligman-Silva (2006). 
anticorpos na pessoa, injeta um pouco de doença no corpo individual. Igualmente a comunidade é "injetada” com uma dose de violência, assim está preparada para um ataque destruidor. Observemos que Luhmann aparece no pensamento do autor italiano, pois uma sociedade, diz Esposito comentando o autor alemão, não vive evitando o conflito, mas resolvendo problemas através dele. Imunizar é saber lidar com conflitos, não cancelá-los. Isto vale internamente e também contra os inimigos, já que a imunidade pode ser uma forma de isolamento, proteção negativa, erigindo limites claros ao que é externo. Com a imunização, a coletividade antecipa problemas, articula leis que possam inocular ameaças, está pronta para o risco antes do contato com "a doença”. Guerra ao terror.

Todavia, é o termo negativo, sem dúvida, que se destaca. Assim, torna-se central na narrativa mostrar que toda imunização é uma proteçáo negativa da vida. Daí a importância que assume o direito e a violência por meio do ensaio de Benjamin. Protege-se ao custo da normalização da vida; violenta-se para criar e manter a lei, ordenar e prevenir o caos.

Entretanto, tão íntimo ao debate filosófico-político italiano atual, Esposito procura deixar transparente em que momento se separa das teses de Agamben (2002 e 2004). As discussóes a respeito da soberania e do Estado de exceção são exemplares. Náo somente "[...] porque ele [o poder soberano] decide [no sentido etimológico de separar] vida de morte, mas, mais profundamente, porque as une numa relaçáo conectando a vida à morte, no limite de fazer da morte o instrumento para preservação da vida” (ESPOSITO, 2011, p. 33). Mais uma vez retorna o argumento da imunização e esta relação simétrica entre imunidade e comunidade (e proteção negativa da vida) que Nalli (2013) observou. $\mathrm{O}$ ponto nodal da biopolítica não é, como para Agamben, ver o quanto o soberano inclui a vida excluindo-a, e sim como a soberania se intersecta com a imunização; soberania supóe uma parte da vida que é sacrificada por outra que domina a primeira de uma forma violenta, tal qual a obra de Agamben mostra (também em RADOMSKY, 2015). Para Esposito, isso não é relevante; a vida como um todo é protegida e "desenvolvida"; contudo, esse processo contém em si mesmo elementos internos contraditórios em que a própria vida passa a depender de uma proteção negativa (ESPOSITO, 2011, p. 138-139)5 .

5 Para uma comparação instrutiva entre Agamben e Esposito quanto ao problema da biopolítica, ver: Georgi e Pinkus, 2006. 
A biopolítica articulada à centralidade da imunidade, em Esposito, indica-nos que a sociedade moderna exige uma crescente prevençáo do perigo via imunizaçáo. No ponto de vista de Oliva (2006), a imunização é como uma comunidade negativa que erige fronteiras contra quaisquer contaminaçóes. A sociedade moderna se orientou a observar e saber lidar com o fato de que no seio da vida há algo que a ameaça, no seio da comunidade há elementos que podem destruí-la.

\section{Bios e Tanatos: a ambivalência da política da vida na modernidade}

Bios foi publicado em 2004 em italiano e investiga o tema da biopolítica quanto a questóes históricas e filosóficas. É a única obra aqui comentada que está publicada em língua portuguesa no momento. Foucault está no palco principal desse teatro, já que na análise das mecânicas do poder a biopolítica aparece como preservação da vida que se sustenta na conhecida fórmula "deixar morrer, fazer viver” (FOUCAULT, 1999). Esposito se pergunta: como uma política da (preservação da) vida leva ao extermínio em massa no século $X X$ ? A ideia de "fazer viver" que caracterizaria a biopolítica é insuficiente. Por isso, para o autor italiano, o que explica este nexo é a imunidade, embora reconheça que Foucault havia elaborado o problema tendo em vista a guerra das raças no século XIX e os artifícios sobre como se elaborou a defesa da sociedade contra suas crescentes ameaças (FOUCAULT, 1999).

Novamente estamos em face desta complexa relaçáo entre comunidade e imunização: está em jogo, nos termos de Esposito, que toda a política da vida (biopolítica) arrisca a se tornar uma política de morte (tanatopolítica). Vida e morte, portanto, andam juntas. Já a imunidade está relacionada a um processo de sacrificar outros para preservar alguns (ou: para manter a vida é preciso matar alguém).

Nos trabalhos de Foucault - especialmente Foucault (2008a); mas, ver também Foucault (2008b) -, aponta Esposito, faltam conexóes transparentes sobre biopolítica e modernidade. A verdade é que ele considera esta uma intersecção problemática, pois o que falta nessa equação é a imunização, espécie de "nó" conceitual que liga biopolítica e o mundo moderno. Imunidade é um 
estado em que, para salvar a vida de um coletivo, a própria vida é tornada absolutamente privada e individualizada (contra o munus, examinado antes).

Como exercício de explicação histórica, Esposito demonstra que o séc. XX testemunha uma reflexão sobre a política em termos absolutamente biológicos, e vemos dois importantes momentos: o nazismo e o pensamento sobre o comportamento político humano que se torna de algum modo difundido nos anos 1960. O caso alemão é conhecido e somente menciono aqui alguns aspectos relevantes da crítica do autor, tal como a linguagem dos cientistas e médicos nazistas preocupados com toda a sorte de problemas bio-sócio-políticos: contágio, parasitas, saúde, tecido (social), corpo político. Portanto, é no nazismo, mais do que nunca, que a biologia do corpo se torna assunto decisivo para a saúde do corpo social. Assim, é radical que se possa interpretar o Estado como táo incisivamente articulado ao social que não seja o Estado que tem a soberania sobre vida e morte, mas qualquer pessoa. Aqui também podem ser percebidas diferenças com o pensamento de Agamben (2002), pois, após mostrar a incrível normativização da vida que o nazismo impóe (juridificação da bios), Esposito discorre sobre o lugar de bios e zoe neste quadro (2010, p. 202). A questáo para Esposito é que no nazismo se impetra uma passagem/ transformação decisiva, a espiritualização da zoe (o corpo social alemão) ou a biologização do espírito, articulada na raça.

A partir deste momento histórico, diferentes autores teriam se referido à imunidade, mas apenas nos anos 1960 que cientistas políticos e biólogos passaram a se referir à biopolítica ${ }^{6}$. Contudo, antes desta época, provavelmente a partir de Nietzsche que, pela primeira vez, o vitalismo seja constitutivo do pensamento político - a vida que deseja se tornar mais e mais forte. Assim, rompendo com as concepçôes anteriores, para o filósofo alemão não é o sujeito, nem a transcendência, sequer o Espírito, a soberania ou o Estado a fonte da ação e reflexão política: é a própria vida que ocupa este espaço. Esposito considera que Nietzsche $(2006,2009)$ antecipou os estudos em biopolítica de Foucault inteiramente, uma vez que abordou acerca da centralidade do corpo “[...] como gênese e término das dinâmicas sociopolíticas, ao papel fundador

6 Mudanças na biopolítica pós-eugenia, conforme Esposito, colocam a vida cada vez mais pressionada pela economia, pela matemática e pela biologia, pois a produtividade humana associada à saúde e a técnicas de controle são assuntos de governo. 
da luta, e também da guerra, na configuração dos ordenamentos jurídico-institucionais, até à função de resistência como contraponto necessário ao desenvolvimento do poder [...]" (ESPOSITO, 2010, p. 127).

Igualmente emblemático para o tópico, Nietzsche teria observado como na história ocidental se construíram modos e técnicas de o ser humano "se proteger" do excesso de vida - um vitalismo que se projeta, dionisíaco, que quer se expandir e pode ser violento, particularmente em Nietzsche (2008).

O vitalismo expansivo de alguns pode aniquilar muitos, até a própria vida. Contra esta vida podendo ser vivida intensamente é que a imunidade e a Lei atuarão. Por isso, Esposito observará a capacidade imunizadora enquanto proteção da vida, uma proteção sempre problemática, pois normaliza o humano e restringe suas "bio-potencialidades".

Após uma passagem importante em Heidegger (examinando o ser-aí e suas relaçóes intrínsecas, sua pura existência no mundo como alternativa à biopolítica), Esposito termina o livro sublinhando possibilidades construtivas através das filosofias de Espinoza, Simondon e Deleuze. A questão é resistir à biopolítica ou há formas de articular biopoderes de maneira que estes não se tornem governos, pastorais e controles sobre população? Existiria o potencial de uma biopolítica afirmativa para nosso tempo? Esposito apostará na ideia de uma política da vida distinta da que temos visto, uma em que emerja sem problemas a capacidade humana de se transformar, sem negar o caráter vitalístico e corporal da existência. Portanto, a questáo para ele é mesmo uma política da vida que seja afirmativa.

Extirpando toda norma que possa ser transcendente à vida - crítica à Lei -, deseja uma imanência em seja possível viver e devir. Como resultado desta aventura, aqui ainda é possível indagar (ou esperar): seria o desafio ético-político de nosso tempo o de tornar-se uma vida?

\section{Ser pessoa}

Na cena enigmática que introduz o livro $O$ Aberto, de Giorgio Agamben, a ilustração nas últimas páginas de uma bíblia hebraica do séc. XIII mostra humanos com cabeça de animais no "banquete messiânico dos justos". A ela o autor atribui uma importância capital, pois Agamben (2013) descreve-a como 
cena que conclui o códice e também a história humana; porém, por que os semblantes animais nas figuras humanas do fim dos tempos? A domesticação do homem pelo homem da qual nos alertou Sloterdijk (2000) - realizada de modo refinado com cultura, educação e literatura - não isentou nossa história recente da experiência da escravidáo, do genocídio, da violência de gênero, do colonialismo. Se o "humanismo" fracassou, isso reverbera na inesperança de existirem indícios para se apostar em um tipo domesticação possível para o reino humano. O caso descrito por Agamben é ilustrativo ou perturbador? O que veremos nesta pós-história será um futuro em que a humanitas terá um encontro não imaginado com sua animalitas? Quiçá uma metamorfose kafkiana que seja desvencilhada da culpa e do julgamento.

Em Third Person (original de 2007), Esposito se orienta para a problemática relaçáo que o mundo ocidental estabeleceu com a noção (e a categoria filosófica) de pessoa. Esta categoria é central para a arquitetura do pensamento ocidental e ampara construçóes posteriores tais como a noçáo de direitos humanos, a ideia de singularidade da vida humana e a sua separaçáo do reino animal. Nessa complexa genealogia, o autor estuda os dispositivos de constituição legal de quem era ou não pessoa na Roma antiga, passando pelas bases do cristianismo, como a mesma discussão foi envolvida pelos processos de secularização e chega até a modernidade.

$\mathrm{Na}$ direção de não cair em antinomias fáceis, Esposito demonstra que o mais expressivo da sua aderência reside no fato de que argumentos cristáos e seculares sobre o assunto se fundamentam em uma mesma tópica: a sacralidade da vida humana somente pode se fundamentar pelo seu caráter de pessoa, distinta de uma natureza subjacente. Observa-se como, por outro caminho conceitual, Esposito encontra mais uma vez o problema da imunização, já que é através dela que na modernidade se amparará para sustentar a unicidade da vida humana e a proteçáo necessária do ser humano contra ele mesmo.

Impessoal será conceito crucial em sua narrativa. Antes disto, no entanto, o autor se debruça, na genealogia, entre as condições filosóficas e as formaçóes científicas que se embasaram nesta categoria e auxiliaram a aprofundar as antinomias dela derivadas. Aqui a antropologia terá um papel relevante, pois teve como aspecto fundante "jogar" o ser humano no reino animal, retirando-o do reino da história para observá-lo enquanto espécie. Esse movimento não teria 
sido possível sem que se estabelecesse uma grande divisão (um salto), na qual a antropologia dialoga com a zoologia e em que o humano deixa o mundo meramente animal para aparecer em uma singularidade. Toda a relaçáo entre pessoa e náo pessoa, táo penetrante no Ocidente, será objeto de decisáo política a cada vez que houver vontade ou necessidade de classificar, separar ou destruir parcelas de população humana.

Essa noção de pessoa ressoa tão profundamente no nosso comportamento que a auto-domesticação humana também se apoia nela; afirma o autor que pessoa é aquela que controla seu "lado animal" (ESPOSITO, 2012, p. 89). Testemunha-se nesse livro, embora possa ser afirmado também para boa parte da sua obra, um alerta para o problema do que a personalização realizou sobre o indivíduo - a sacralização da persona, da máscara que se erige sobre o fundo bios do humano e que será negado ou domesticado, eventualmente utilizado para dispor ontologicamente os seres enquanto pessoas, semipessoas e não pessoas (embriôes, gametas, escravos etc). A filosofia da pessoa ou da personalização é a mesma que possibilita a imunidade do indivíduo capaz de proteger a vida negativamente. Para tal, Esposito não se lança no seu revés, ou seja, em uma filosofia da despersonalizaçáo. Esta é apenas o outro lado sombrio da anterior, a que possibilita a tanatopolítica e que lidou com a noção de pessoa estrategicamente, para dispô-la eventualmente e transformar pessoas em massas, coisas, zoe; esta se fundamenta em uma espécie de filosofia da “anti-pessoa". Por esta razáo que os escritos de Simone Weil e Gilles Deleuze ${ }^{7}$ estão tão presentes, e o que se coloca em jogo são as potencialidades políticas e filosóficas do impessoal.

Sendo necessariamente econômico nas palavras neste ensaio, pode-se brevemente observar que, nas palavras do autor, "[...] o impessoal reside fora do horizonte da pessoa, mas não num lugar que não esteja relacionado a ela: o impessoal está situado, antes, nos confins do pessoal; nas linhas de resistência [...]" (ESPOSITO, 2012, p. 14). A noçáo de impessoal vem a prevenir e se opor ao funcionamento do dispositivo excludente próprio da personalização. O impessoal é uma fronteira movente e de mudança, ele opera bloqueando

7 Diversas referências importam para Esposito, mas cabe mencionar apenas um: o belo liuro de Alain Badiou sobre Gilles Deleuze (BADIOU, 1997), lembrado pelo próprio autor italiano justamente por tão bem expor as questões em torno do impessoal, do virtual e da lógica da imanência. 
as tentativas reificadoras da pessoa. Mais adiante, Simone Weil será recuperada para sugerir que tudo aquilo que é impessoal no ser humano é sagrado; o impessoal e o anônimo, o que não é identificado e está antes de qualquer personificaçáo subjetiva, é objeto de justiça (ESPOSITO, 2012, p. 101-102). "Antes de destruir a pessoa [...]", indica Esposito, “[...] o trabalho conceitual da 'terceira pessoa' significa criar uma abertura para um conjunto de forças que a empurra para além de suas fronteiras lógicas e até mesmo gramaticais" (ESPOSITO, 2012, p. 14).

Fica mais claro para nós, leitores, o quanto a conexão Nietzsche-Battaille - exposta nos livros anteriores - é uma peça-chave para Esposito, pois a experiência da corporalidade, da vitalidade associada ao prazer e a uma dessubjetivação que leva o sujeito para fora de si parece ser uma esperança para Esposito, uma aposta na bio-potencialidade, na incessante transformaçáo do humano e de sua vida na "comunidade política".

\section{Considerações finais}

Em Communitas, somos apresentados a caminhos que se organizam em torno de uma experiência na qual a comunidade não venha a se erigir como um edifício que encapsula as pessoas. Immunitas sugere a importante passagem sobre as coincidências entre Lei/lei e vida que nos leva a imaginar outras relaçóes entre a norma e o viver possam ser desejadas. Bios mostra uma continuidade fascinante com o final de Communitas, orientada por Deleuze e Simondon, uma superabundância de possibilidades de construçóes do viver em que se recupere o caráter vitalístico e afirmativo do corpo. Roberto Esposito, a cada finalle, remete para uma experiência da nossa espécie que se afirme em um devir intenso; porém, que náo seja, tal como alerta Sloterdijk antes citado, uma substituição da biopolítica pela tanatopolítica ou por uma zoopolítica. Importa, como anotou Oliva (2006, p. 82), uma política da vida que potencialize o humano com "the power to be otherwise".

Para finalizar este ensaio com Third Person, parece haver uma ligação inesperada (indireta) com a pintura da bíblia antes comentada por Agamben. A animalidade do humano poderia fazer emergir uma nova forma de vida? Olha-se em direçáo ao futuro, como escreve o autor, náo para a aurora do Homem: "[...] antes de uma simples reanimalização do agora humano 
humanizado, é um caminho para ser humano que não mais se define em termos de alteridade da nossa origem animal" (ESPOSITO, 2012, p. 114). O devir-animal do humano não é um retorno ao primevo, mas um mundo nunca antes experimentado.

\section{Referências}

AGAMBEN, G. Homo Sacer: o poder soberano e a vida nua I. Belo Horizonte: Editora UFMG, 2002.

. Estado de exceção. São Paulo: Boitempo, 2004.

O que resta de Auschwitz: o arquivo e a testemunha (Homo Sacer, III). São Paulo: Boitempo, 2008.

O aberto: o homem e o animal. Rio de Janeiro: Civilização Brasileira, 2013.

BADIOU, A. Deleuze: o clamor do ser. Rio de Janeiro: Jorge Zahar, 1997.

BARBOSA, J. A crítica da violência de Walter Benjamin: implicaçóes histórico-temporais do conceito de reine Gewalt. Revista de Filosofia Aurora, v. 25, n. 37, p. 151-169, jul./dez. 2013.

BENJAMIN, W. O narrador. Consideraçôes sobre a obra de Nikolai Leskov. In:

Obras escolhidas - magia e técnica, arte e literatura: ensaios sobre literatura e história da cultura. São Paulo: Brasiliense. Tradução de Sergio Rouanet. 4. ed. 1985a. v.1. p. 197-221.

Experiência e pobreza. In:

Obras escolhidas - magia e técnica, arte e

literatura: ensaios sobre literatura e história da cultura. São Paulo: Brasiliense. Traduçáo de Sergio Rouanet. 4. ed. 1985b. V. 1. p. 114-119.

O anjo da história. 2. ed. Belo Horizonte: Autêntica, 2013.

CAMPBEL, T. Bios, immunity, life: the thought of Roberto Esposito. In: ESPOSITO, Roberto. Bíos: biopolitics and philosophy. Minneapolis: Minnesota University Press, 2008. p. vii-xlii.

DONÀ, M. Immunity and negation: on possible developments of the theses outlined in Roberto Esposito's Immunitas. Diacritcs, v. 36, n. 2, p. 57-69, 2006.

ESPOSITO, R. Communitas: origen y destino de la comunidad. Buenos Aires: Amorrortu Editores, 2003. 
Immunitas: the protection and negation of life. Cambridge; Malden: Polity Press, 2011.

Bios: biopolítica e filosofia. Lisboa: Ediçóes 70, 2010.

Third person: politics of life and philosophy of the impersonal. Cambridge; Malden: Polity Press, 2012.

FOUCAULT, M. Em defesa da sociedade. Curso no Collège de France (1975-1976). São Paulo: Martins Fontes, 1999.

Segurança, território, população: Curso no Collège de France (1977-1978). São Paulo: Martins Fontes, 2008a.

O nascimento da biopolítica. Curso no Collège de France (1978-1979). São Paulo: Martins Fontes, 2008b.

GEORGI, G.; PINKUS, K. Zones of exception: biopolitical territories in the neoliberal era. Diacritcs, v. 36, n. 2, p. 99-108, 2006.

NALLI, M. Communitas/Immunitas: a releitura de Roberto Esposito da biopolítica. Revista de Filosofia Aurora, v. 5, n. 37, p. 79-105, jul./dez. 2013.

NANCY, J-L.The inoperative community. Minneapolis: University of Minnesota Press, 1991.

Conloquium. In: ESPOSITO, R. Communitas: origen y destino de la comunidad. Buenos Aires: Amorrortu Editores, 2003. p. 9-19.

NIETZSCHE, F. W. A gaia ciência. São Paulo: Escala, 2006.

Assim falava Zaratustra: um livro para todos e para ninguém. 6. ed. Petrópolis: Vozes, 2008.

A genealogia da moral. São Paulo: Vozes, 2009.

OLIVA, R. From the immune community to the communitarian immunity: on the recent reflections of Roberto Esposito. Diacritcs, v. 36, n. 2, p. 70-82, 2006.

RADOMSKY, G. Biopolítica e desenvolvimento? Foucault e Agamben sobre Estado, governo e violência. Dados, v. 58, p. 537-567, 2015.

SELIGMAN-SILVA, M. Walter Benjamin: o Estado de exceção entre o político e o estético. Outra Travessia, v. 5, p. 25-38, 2006. 
SLOTERDIJK, P. Regras para o parque humano: uma resposta à carta de Heidegger sobre o humanismo. São Paulo: Estação Liberdade, 2000.

\section{Roberto Esposito: community, biopolitics and immunization}

\section{Abstract}

In this essay, I examine four books from Roberto Esposito (Communitas, Immunitas, Bios e Third Person) through the axis 'life - immunity - experience'. The analysis articulates these three issues to two central problems concerning his writings: biopolitics and community. The aim is to discuss aspects from these books that operate relevant reflections about the contemporary politics. Esposito analyzes biopolitics differently from other important researchers who approach the subject, such as Foucault and Agamben, and his original contribution is in articulating it to the problem of immunization.

Keywords: Biopolitics. Experience. Immunization paradigm.

Recebido em: 05/09/2015

Aceito em: 10/12/2016 